\title{
Disease severity of 100 patients with systemic sclerosis over a period of 14 years: using a modified Medsger scale
}

\author{
Á J Geirsson, F A Wollheim, A Åkesson
}

\begin{abstract}
Objective-To assess organ involvement according to a modified Medsger severity scale and its relation to outcome and prognosis in patients with systemic sclerosis.

Methods-One hundred consecutive patients observed in Lund with systemic sclerosis were followed up for a period of 14 years. The mean follow up time was 7.7 years. Initial assessment and an annual evaluation was performed for each patient, with a mean visit frequency of 5.6 per patient.
\end{abstract}

Results-Age at referral, high total skin score, truncal skin involvement, low vital capacity, low static lung compliance, low Cr-EDTA clearance, and ECG abnormalities at the initial assessment predict poor outcome. A severity scoring system for five organ systems indicates a slow progression of organ dysfunction after recruitment into the study. The female: male ratio was $2: 1$, the mean age at onset of symptoms was 42.3 (range 3-82), and the mean age at recruitment was 47.2 years (range 17-82). Thirty patients died during the follow up period at the mean age of 61.3 years (range 33-85). The causes of death were directly related to systemic sclerosis in at least 10 patients, infections in six, cancers in nine, and other causes in four patients. The standardised mortality ratio was 3.5 and 3.7 for men and women, respectively.

Conclusion-A high severity score for function of vital organs was shown to predict shortened survival. In this study a severity score based on simple clinical assessment variables was able to predict poor outcome from extensive skin changes, ECG changes, and compromised lung and renal function. Organ dysfunction mainly became manifest during the first five years of the disease, whereafter organ function remained largely stable. (Ann Rheum Dis 2001;60:1117-1122)

Systemic sclerosis (SSc) is a rare disease that causes excessive collagen deposition and fibrosis in skin and internal organs. Endothelial cell alteration with vasomotor instability, permeability changes and thickening of the intimal layer of arterioles, and perivascular mononuclear cell infiltration are present before fibrosis is apparent in target organs. Inflammation and fibrosis in internal organs can cause organ failure and premature death. ${ }^{1}$ Predicting outcome for an individual patient with scleroderma is not easy because the disease can be heterogeneous in its presentation. The spectrum of the disease ranges from rapidly progressive generalised fibrosis of the skin and vital internal organs like heart, lungs, gastrointestinal tract, and kidneys to a more indolent form developing over a long period of time. ${ }^{2}$ The prognosis is affected by cutaneous, and internal organ involvement and other factors, and although no cure is available for SSc, certain disease manifestations like vasomotor instability, hypertension, cardiopulmonary dysfunction, and oesophageal problems can be treated..$^{3-7}$ Treatment targeting affected organs may alter the long term outcome of the disease. This is supported by improved survival in some recent reports ${ }^{89}$ compared with earlier studies. ${ }^{1011}$ Early active treatment is in need of better clinical or laboratory based measures of severity and prognosis. In cooperation with other European and North American units, we worked on a severity index as a first step to this end. ${ }^{12}$ However, only longitudinal observation over extended time periods can provide a test of how useful such an instrument may be. In this structured cohort study 100 consecutively admitted patients with scleroderma were followed up for a period of 14 years, and prognosis and outcome evaluated by organ involvement and laboratory variables, using a scoring system similar to the European, North American one. ${ }^{12}$

\section{Patients and methods}

One hundred consecutively admitted patients with SSc, fulfilling the American Rheumatism Association criteria, ${ }^{13}$ were followed up in Lund from January $1982^{14}$ to December 1995. The mean follow up time was 7.7 years (range 0.3-12.8); 64 patients were followed up for more than five years. The mean visit frequency was 5.6 per patient. The patients were divided according to skin involvement. Thus 66 patients had limited and 34 had diffuse SSc. Table 1 shows the demographic data. Disease onset was defined as the beginning of skin involvement.

\section{SKIN ASSESSMENT}

Skin involvement was determined by palpation over 24 anatomical sites, and grading the findings on a $0-3$ scale, with 0 being normal and 3 hidebound dermal sclerosis. The scores for all sites were added, giving the total skin score. The mean skin thickness of the proximal and 
Table 1 Demographic data on 100 patients with systemic sclerosis (SSc). Results given as mean (range)

\begin{tabular}{ll}
\hline Female/male ratio & $67 / 33=2: 1$ \\
Mean age at onset (years) & $42.4(3-82)$ \\
Mean age at recruitment (years) & $47.2(11-82)$ \\
Mean age at onset for non-survivors (years) & $48.7(14-82)$ \\
Mean age at onset for survivors (years) & $39.7(3-67)$ \\
Mean age in years at death (30 patients) & $61.3(33-85)$ \\
No of patients with 1SSc/dSSc & $66 / 34$ \\
Mean follow up time (years) & $7.7(0.3-12.8)$ \\
Mean number of visits & $5.6(1-12)$ \\
\hline
\end{tabular}

middle phalanx of both second fingers was examined with dynamic $10 \mathrm{MHz}$ ultrasound. ${ }^{15}$

LUNG FUNCTION

Vital capacity (VC) was measured with a water-filled spirometer and total lung capacity was measured with body plethysmography. Static lung compliance (Cst) was measured over the pressure interval $5-15 \mathrm{~mm} \mathrm{H}_{2} \mathrm{O}$; these variables were expressed in relation to predicted values in age and sex matched healthy subjects. ${ }^{16}$

RENAL FUNCTION

Glomerular filtration rate was determined by

${ }^{51} \mathrm{Cr}$-EDTA clearance expressed as $\mathrm{ml} / \mathrm{min}$.

GASTROINTESTINAL TRACT FUNCTION

Oesophageal function was assessed by cinematography, repeated boluses of barium were swallowed. Motility was recorded with the patient in a prone position, and graded on a 0-3 scale, where 0 was normal oesophageal function and 3 signified complete absence of propulsive motility. A fat meal containing $\left[{ }^{14} \mathrm{C}\right]$ triolein was given to the patient after an overnight fast. Breath ${ }^{14} \mathrm{CO}_{2}$ was collected at two, four, five, and six hours. Peak expiratory ${ }^{14} \mathrm{CO}_{2}$ (percentage of a given dose/h) was used as a measure of fat absorption. ${ }^{17}$

\section{CARDIAC FUNCTION}

Cardiac function was assessed by ECG; the most common changes were ST or $\mathrm{T}$ wave changes, followed by bundle branch block, hemiblock, and septal infarction pattern. Acrolysis and calcinosis were assessed by $x$ ray examination. Erythrocyte sedimentation rate expressed in $\mathrm{mm} / \mathrm{lst} \mathrm{h}$, haemoglobin $(\mathrm{g} / \mathrm{l})$, creatinine $(\mu \mathrm{mol} / 1)$, and antinuclear antibody (rat liver substrate) expressed as inverse titre, titrated to the highest dilution, were performed as routine in the laboratory of the hospital.

DISEASE SEVERITY SCORING SYSTEM

We constructed a disease severity scoring system adapted from a recently developed severity scale by Medsger et al based on assessing the function of five organ systems. ${ }^{12}$ We use different organ function assessment techniques in some instances from those reported in Medsger's paper. Thus the function severity score of some organs had to be omitted because of lack of recorded data. This applied to peripheral vascular organs, joint/tendon, muscle, and heart. In other instances we used a different measuring system. For general health we used haemoglobin instead of packed cell volume and weight loss. Skin score was determined by palpation over 24 anatomical sites, identical with those defined by Rodnan, but using $0-3$ instead of a $0-4$ scale. This

Table 2 Severity index scoring system of organ function in patients with systemic sclerosis (SSc). The definition of the categories used is given below. For each organ system grades of 0 (no involvement)-4 (end stage failure). Scoring system used to assess survival function

\begin{tabular}{|c|c|c|c|c|c|}
\hline \multirow[b]{2}{*}{ Organ system score } & \multicolumn{5}{|c|}{ Severity index score in patients with systemic sclerosis } \\
\hline & $\begin{array}{l}\text { No } \\
\text { involvement }=0\end{array}$ & $\begin{array}{l}\text { Mild } \\
\text { involvement }=1\end{array}$ & $\begin{array}{l}\text { Moderate } \\
\text { involvement }=2\end{array}$ & $\begin{array}{l}\text { Severe } \\
\text { involvement }=3\end{array}$ & $\begin{array}{l}\text { End stage } \\
\text { failure }=4\end{array}$ \\
\hline \multicolumn{6}{|l|}{ General } \\
\hline Haemoglobin $(\mathrm{g} / \mathrm{l})$ & $>120$ & $110-120$ & $95-110$ & $75-95$ & $<75$ \\
\hline Skin score $0-72$ & 0 & $1-19$ & $20-39$ & $40-59$ & $>60$ \\
\hline \multicolumn{6}{|l|}{ Gastrointestinal function } \\
\hline Oesophageal cinematography and & 0 & $1-2$ & 3 & 3 & 3 \\
\hline Triolein test ( $\%$ of a given dose $/ \mathrm{h})$ & & & $>1.5$ & $1.0-1.5$ & $<1.0$ \\
\hline \multicolumn{6}{|l|}{ Lung function } \\
\hline Vital capacity (\% of normal) or & $>80$ & $70-80$ & $50-69$ & $40-49$ & $<40$ \\
\hline compliance (\% of normal) & $>60$ & $40-60$ & $20-39$ & $10-19$ & $<10$ \\
\hline \multicolumn{6}{|l|}{ Renal function } \\
\hline Cr-EDTA clearance (ml/min) & $80-120$ & $50-79$ & $25-49$ & $10-24$ & $<10$ \\
\hline
\end{tabular}

Table 3 Variables in relation to prognosis in 100 patients with systemic sclerosis, first visit clinical assessment, mean follow up time 7.7 years

\begin{tabular}{|c|c|c|c|c|}
\hline & $\begin{array}{l}\text { No of patients } \\
\text { examined, survivors/ } \\
\text { non-survivors }\end{array}$ & Survivors & Non-survivors & $\begin{array}{l}\text { Statistical } \\
\text { significance } \\
\text { (p value) }\end{array}$ \\
\hline Age at referral (years) & $70 / 30$ & $44.5(12.4)$ & $53.7(15.1)$ & 0.002 \\
\hline Total skin score & $66 / 29$ & $13.0(10.6)$ & $19.2(11.8)$ & 0.012 \\
\hline Vital capacity (\% expected) & $66 / 29$ & $87.4(15.3)$ & $75.2(17.2)$ & $<0.001$ \\
\hline Total lung capacity (\% expected) & $63 / 29$ & $89.5(14.8)$ & $77.7(14.8)$ & $<0.001$ \\
\hline Static lung compliance (\% expected) & $59 / 28$ & $76.0(29.1)$ & $54.6(23.9)$ & $<0.001$ \\
\hline Cr-EDTA clearance $(\mathrm{ml} / \mathrm{min})$ & $64 / 28$ & $90.3(16.9)$ & $76.9(24.4)$ & $<0.003$ \\
\hline Blood pressure systolic (mm Hg) & $69 / 30$ & $135.4(20.9)$ & $141.7(19.1)$ & NS \\
\hline Blood pressure diastolic $(\mathrm{mm} \mathrm{Hg})$ & $69 / 30$ & $81.5(9.9)$ & $82.2(8.9)$ & NS \\
\hline Haemoglobin $(\mathrm{g} / \mathrm{l})$ & $70 / 30$ & $130.9(15.9)$ & $130.2(17.6)$ & NS \\
\hline Erythrocyte sedimentation rate $(\mathrm{mm} / 1 \mathrm{st} \mathrm{h})$ & $70 / 30$ & $17.6(15.2)$ & $25.1(21.8)$ & NS \\
\hline Creatinine $(\mu \mathrm{mol} / \mathrm{l})$ & $70 / 30$ & $74.3(21.8)$ & $79.4(30.7)$ & NS \\
\hline Antinuclear antibody (inverse titre) & $67 / 29$ & $1309.7(3461.4)$ & $3341.7(9820.9)$ & NS \\
\hline
\end{tabular}

Values are expressed as means (SD).

$\mathrm{p}<0.01$ is significant, NS is non-significant. 
Table 4 Proportion of abnormal or normal variables among non-survivors. Figures refer to number of patients

\begin{tabular}{lllc}
\hline & $\begin{array}{l}\text { Abnormality present } \\
\text { Total (non-survivors) }\end{array}$ & $\begin{array}{l}\text { Abnormality absent } \\
\text { Total (non-survivors) }\end{array}$ & $\begin{array}{c}\text { Statistical significance } \\
(p \text { value) }\end{array}$ \\
\hline Calcinosis & $27(12)$ & $63(15)$ & 0.087 \\
Digital ulcers & $12(6)$ & $29(6)$ & 0.134 \\
Acrolysis & $21(8)$ & $58(17)$ & 0.639 \\
Telangiectasia & $67(22)$ & $14(3)$ & 0.601 \\
ECG & $32(18)$ & $61(9)$ & $<0.0001$ \\
Oesophageal dysmotility by cinematography & $69(22)$ & $30(7)$ & 0.54 \\
Scleroderma on the trunk & $34(17)$ & $66(13)$ & 0.004
\end{tabular}

results in a theoretical range from $0-72 .{ }^{13} \mathrm{Cin}-$ ematography and the triolein breath test were used to assess involvement of the gastrointestinal tract. Lung function was graded by VC and Cst instead of carbon monoxide transfer factor and forced vital capacity and renal function by Cr-EDTA clearance instead of serum creatinine and urine analysis in the Medsger severity scale. ${ }^{12}$ In all instances an effort was made to make our scoring of organ function comparable with the severity scale of Medsger et al. Organ function was graded in five grades: 0 (no documented involvement), 1 (mild involvement), 2 (moderate involvement), 3 (severe involvement), and 4 (end stage organ failure). Table 2 shows the grades by which the criteria

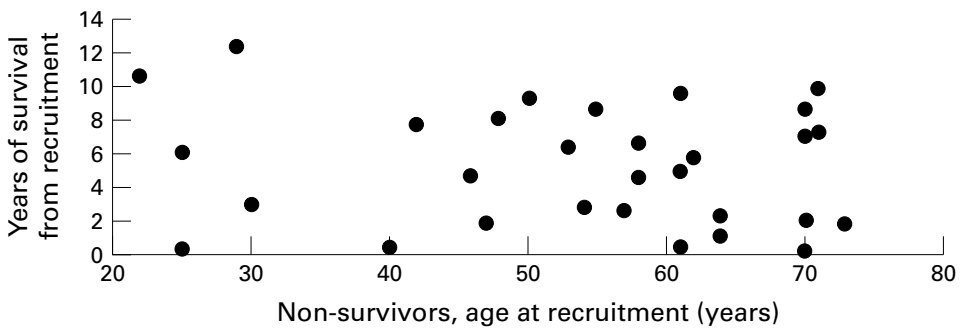

Figure 1 Survival time in non-survivors. Within six years from recruitment into the study 16 of 30 non-survivors died, 2/3 of them were over 50 years of age at the time of death.

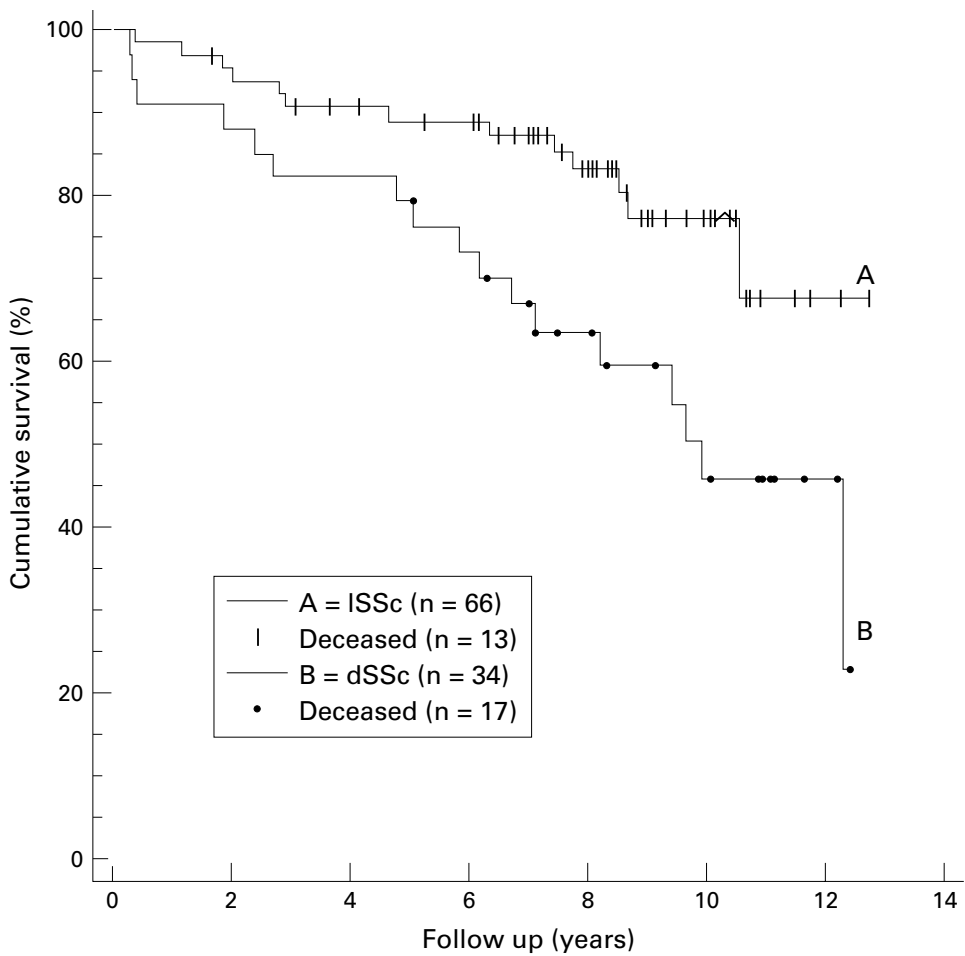

Figure 2 Kaplan-Meier cumulative survival plot. Skin involvement as a determinant of survival in systemic sclerosis. Improved survival for patients with limited systemic sclerosis $(p=0.015)$. were defined. Scoring was performed at inclusion in the study and thereafter at each visit. A Kaplan-Meier survival analysis was used to test the effect of the severity score on survival.

CAUSES OF DEATH

The causes of death and its relation to SSc were subdivided according to the following four categories: (a) unequivocally SSc related, death caused by organ failure; (b) probably SSc related, death caused by a complication caused or aggravated by SSc related to organ injury or treatment; (c) possibly SSc related, death caused by a manifestation reported to have a greater prevalence in SSc - for example, malignancy or suicide; (d) death apparently unrelated to SSc, treatment or organ involvement. ${ }^{9}$

STATISTICS

Logistic regression univariate model and the $\chi^{2}$ test were used to assess the effect of different variables on prognosis.

\section{Results}

Demographic data are shown in (table 1). During the 14 year follow up 30 of the 100 patients had died, at a mean age of 61.3 years (range 33-85). There was no difference in survival according to sex, but patients with 1SSc had longer survival than those with dSSc. When assessment at first visit was used as a reference, the following variables were predictors of non-survival. Older age at inclusion, higher skin score, reduced VC, reduced total lung capacity, and reduced Cst, were significant predictors of fatal outcome. This also applied to low Cr-EDTA clearance and abnormal electrocardiogram (ECG). No other laboratory variables nor the presence of acrolysis, digital ulcers or telangiectasia were found to have any prognostic implication (tables 3 and 4).

There was an inverse correlation between skin score and VC $(\mathrm{p}<0.001)$, and age and Cr-EDTA clearance $(\mathrm{p}<0.001)$. There was a correlation between VC and Cr-EDTA clearance $(p=0.001)$, and inverse correlation between Cr-EDTA clearance and the formation of calcium deposits $(\mathrm{p}=0.016)$.

Table 2 shows the severity scoring system. No mean change in the severity index score was observed for Cr-EDTA in $81 \%$, for VC/Cst in $71 \%$, for cinematography $/\left[{ }^{14} \mathrm{C}\right]$ triolein in $75 \%$, for skin score in $75 \%$, and haemoglobin in $80 \%$ of the patients during the follow up period. The mean time from the onset of symptoms to recruitment into the study was 4.8 years (table 1). Figure 1 illustrates years of survival after 
recruitment, and deaths related to age, showing that $50 \%$ of the patients that die do so within the first five years after recruitment.

By using Kaplan-Meier cumulative survival plots, we estimated survival function according to initial organ system severity score for each of

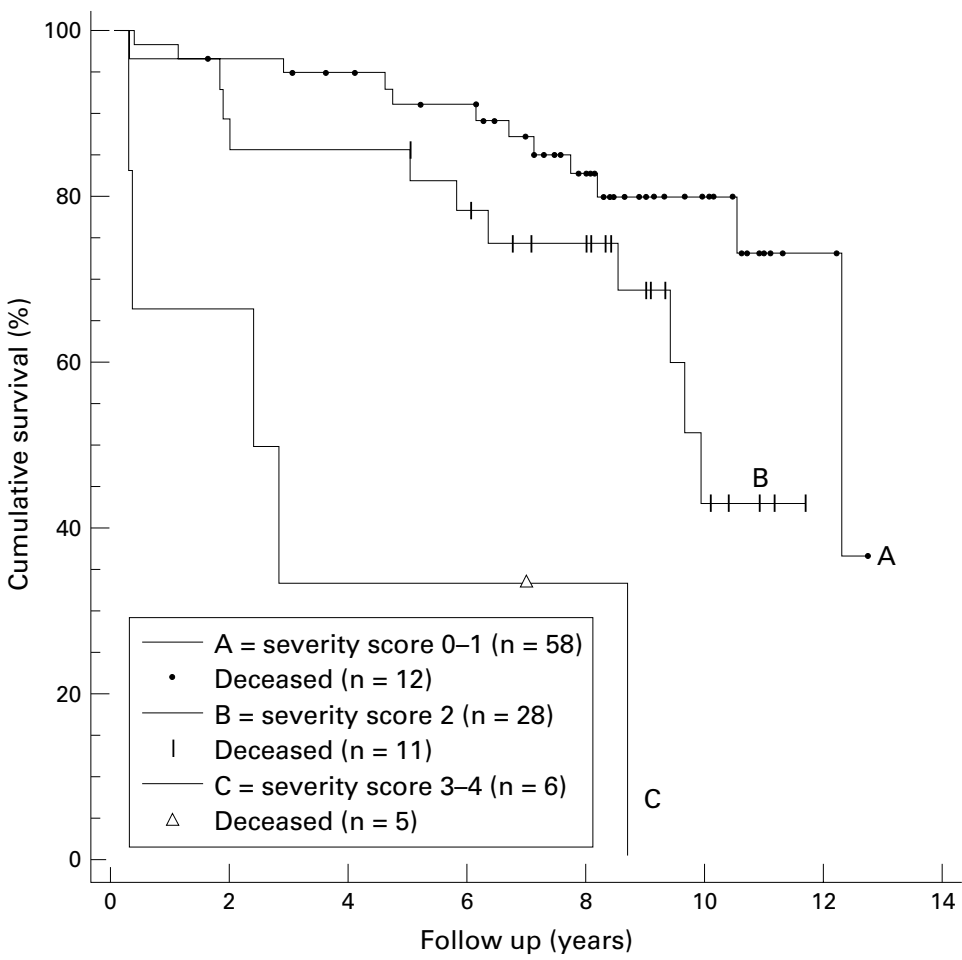

Figure 3 Kaplan-Meier cumulative survival plot. Renal function measured by Cr-EDTA clearance as a determinant of survival in systemic sclerosis, grouping of patients according to severity score $0-1,2$, and 3-4. There is a significantly improved survival for those with severity score of $0-1$ compared with severity score $2(p<0.001)$.

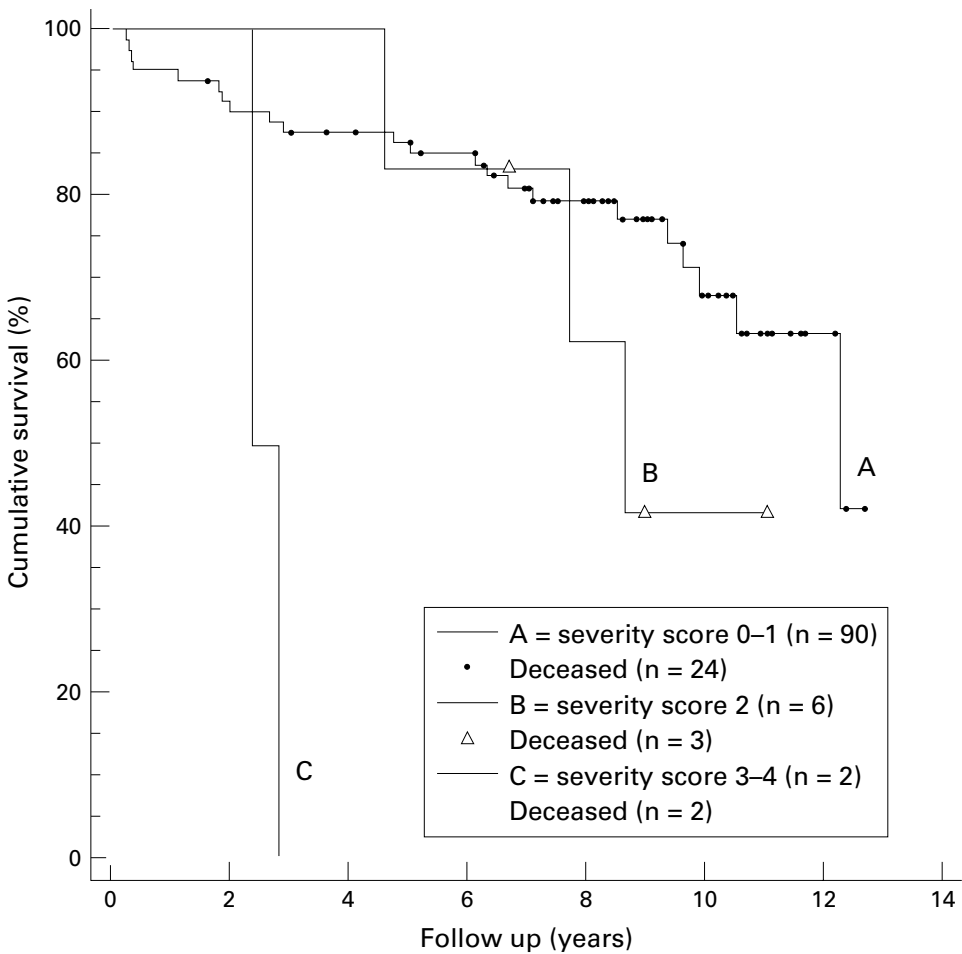

Figure 4 Kaplan-Meier cumulative survival plot. Haemoglobin as a determinant of survival in systemic sclerosis. There is a significantly improved survival for patients with severity score of $0-1$ compared with severity score $2(p=0.0003)$. the five organ systems, and type of disease, during the period of follow up. Diffuse skin involvement was as expected a prognostic factor, with a significantly decreased patient survival compared with those with limited skin involvement (fig 2). When skin score was used as a determinant of survival no difference in survival for patients with severity score $0-1$ and severity scores 2 and 3-4 was seen. When Cr-EDTA clearance was taken as a determinant of survival, patients with a severity score of $0-1$ had better survival than patients with severity score 2 or more (fig 3 ). Haemoglobin as a determinant of survival differentiated between patients with score $0-1$ and score 2 (fig 4). VC and Cst as a measure of lung function were variables that differentiated for survival between patients with severity score $0-1$, severity score 2 , and severity score $3-4$ (fig 5). Difference in survival was also seen over time between groups with variable gastrointestinal function (fig 6).

Mortality was analysed according to the causes of death and its relationship with SSc. Ten deaths were judged as definitely related to SSc, four of which were due to intrinsic lung disease with respiratory insufficiency and four further cases to cardiac failure considered to be secondary to scleroderma heart disease, one of those had acute effusive pericarditis with cardiac compression as a contributory cause. One death was due to pulmonary hypertension, and one was caused by scleroderma renal crisis. Six patients died from infections probably related to SSc. Three of these had intrinsic lung disease and terminal pneumonia. Peritonitis secondary to intestinal perforation occurred in one case, one died of septicaemia, and one died of meningitis. Most deaths because of causes possibly related to SSc were attributable to lung cancer $(n=4)$ and myocardial infarction $(n=2)$, one patient died of haemolytic anaemia and one of suicide. Of the deaths not considered to be related to SSc five were due to cancer, of breast $(n=2)$, pancreas, liver and uterus, and one died of stroke. The overall standardised mortality ratio was 3.5 and 3.7 for men and women, respectively. The group of patients who died were older at the time of diagnosis (mean age 48.7 years (range 14-74)) than the group as a whole (table 1).

\section{Discussion}

This study examined a series of unselected patients with SSc in whom the outcome could be assessed in $100 \%$ of cases 14 years after the initial observation. Owing to the gradual onset of the disease as well as to variability in referral practices, the disease onset was estimated to have occurred four to five years before actual inclusion. Thus our study is not informative about very early disease developments. This is common to several other studies. ${ }^{18}{ }^{19}$ It was possible to identify dermal, pulmonary, cardiac, renal, and gastrointestinal variables with influence on survival. We cannot exclude the possibility that any of the organ involvement variables might have been more sensitive predictors than others in earlier phases of the 


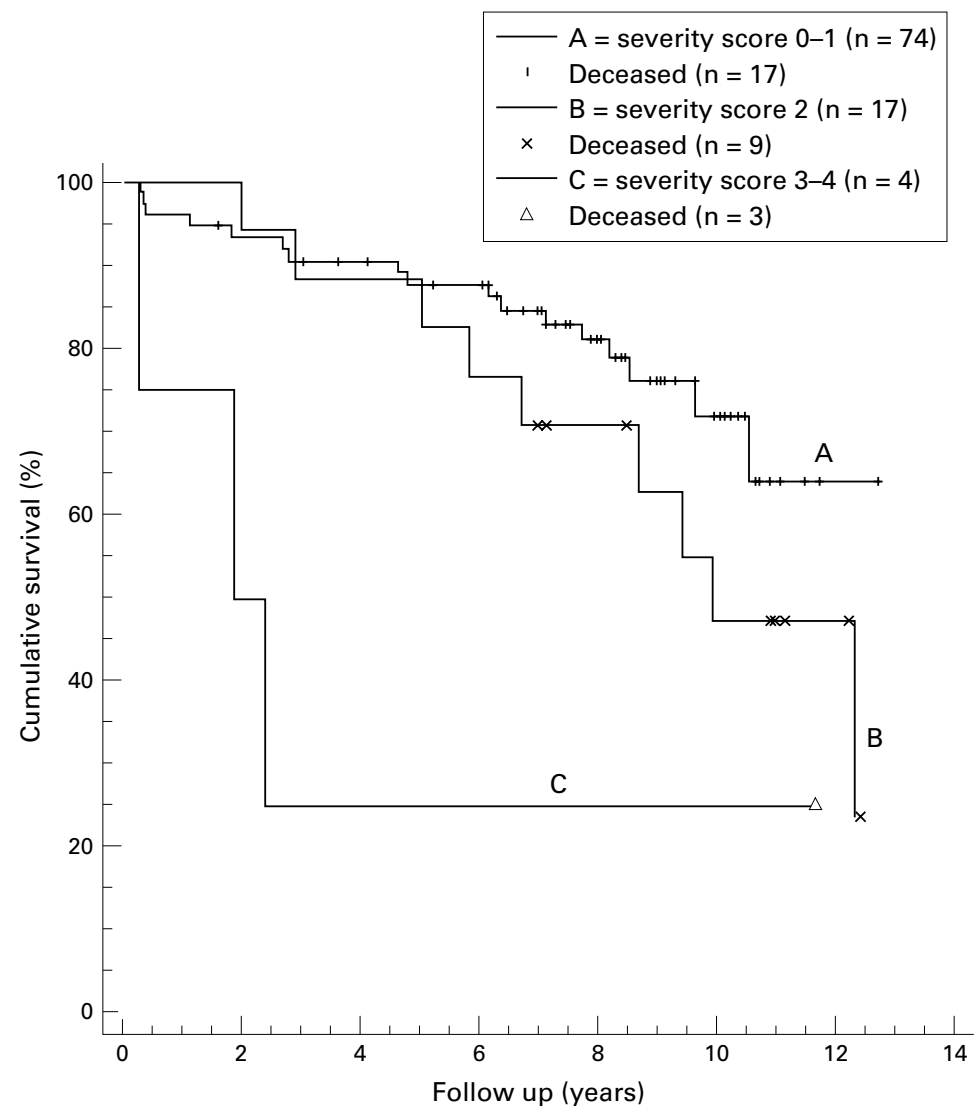

Figure 5 Kaplan-Meier cumulative survival plot. Lung function measured by vital capacity and static lung compliance as a determinant of survival in systemic sclerosis. Grouping of patients according to severity score 0-1, 2, and 3-4. Improved survival for those patients with severity score of $0-1$ compared with severity scores 2 and 3-4 $(p=0.0077)$.

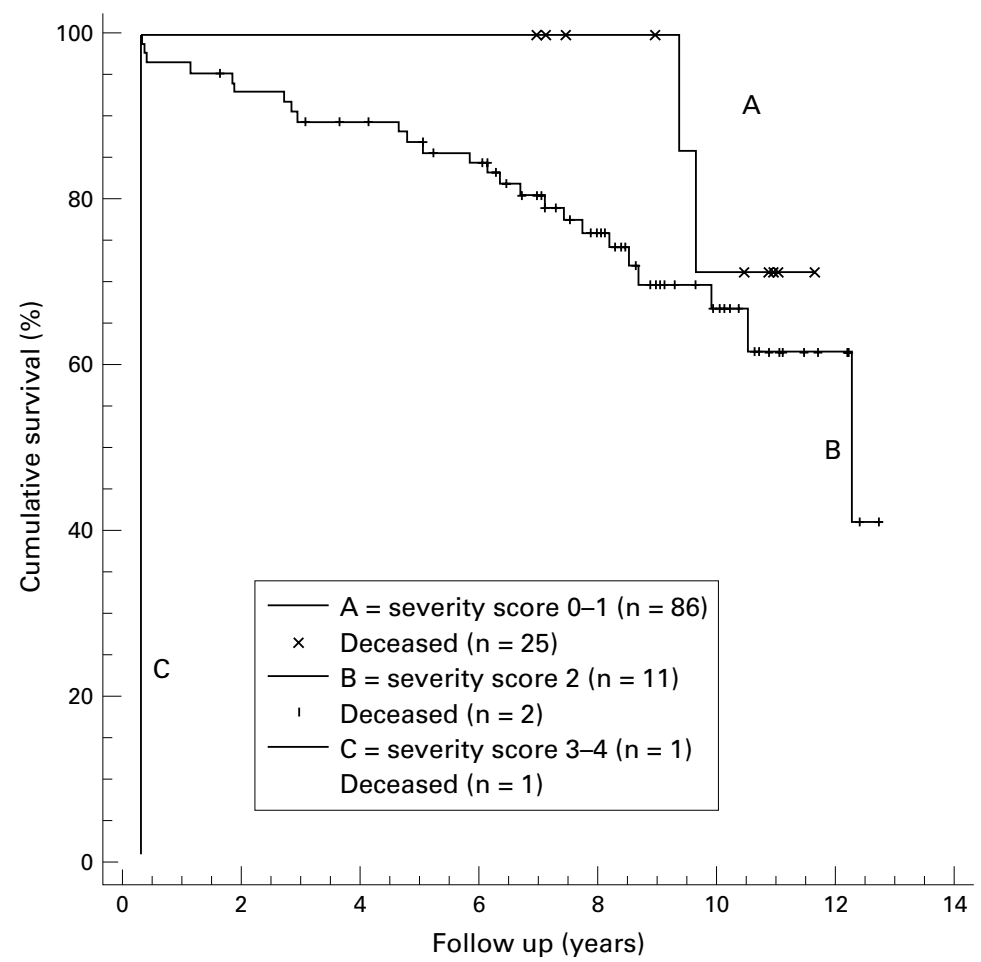

Figure 6 Kaplan-Meier cumulative survival plot. Gastrointestinal function measured by cinematography and triolein test as a determinant of survival in systemic sclerosis. Grouping of patients according to severity score 0-1, 2, and 3-4, showing improved survival for patients with severity score of $0-1$ compared with severity scores 2 and 3-4 $(p<0.0001)$. disease, with the exception of truncal skin involvement.

One important message of the longitudinal observations is the relative stability of organ functions over the observation time. This is not explained by the insensitivity to change of the instrument, but emphasises the fact that in $70-80 \%$ of the patients organ damage had already reached a plateau at inclusion. Such data are obviously important for the proper design and evaluation of therapeutic studies. Other investigators have made similar observations. ${ }^{102021}$ Nevertheless, negative changes in organ function score were seen in $9-11 \%$ of the patients and, with the exception of skin score, these changes also correlated with mortality. We did not explore the potential of a composite organ score, which possibly would have been more sensitive, but would have blurred the distinction between influences from different organ manifestations. Current therapeutic approaches often target individual organ disease owing to a lack of means to influence general disease activity.

The dominating group of patients in our series are women with 1SSc. This group has a rather benign disease, with a standardised mortality ratio lower than the group as a whole, but men with $1 S S c$ have a standardised mortality ratio not different from that of the general population. Consequently, this group should not as a rule be exposed to therapeutic trials with potentially dangerous drugs. However, the subjects within this group whose disease does progress need to be identified as early as possible. Thus changes in a severity score may be of clinical help, and this hypothesis should be put to the test.

The dominating cause of death in this as in other recent series ${ }^{20-23}$ is related to pulmonary disease. Therefore it was of particular interest that the severity score for pulmonary disease correlated with outcome and differentiated between the patients with scores of $0-1,2$, and 3-4, respectively. Because treatment of pulmonary fibrosis with cyclophosphamide and similar toxic drugs is increasingly used, it is important to have reliable clinical instruments to select and monitor these patients.

Our data confirm that simple ECG registration can identify patients with early cardiac mortality, although this occurred with low frequency. Thus cardiac exercise tests may not be necessary in routine clinical practice. Distribution of skin involvement is the main distinguishing feature between 1SSc and dSSc, and thus of undisputed prognostic value. However, changes in skin involvement in advanced disease are not informative about the disease course in most patients, and we and others ${ }^{24}$ have recorded the apparent discrepancy between improvement in skin score and worsening of internal organ involvement. In a multicentre study with a follow up of 264 patients with SSc for an average of 5.2 years, Altman et al found that renal, cardiac, pulmonary, and gastrointestinal disease predicted reduced survival. ${ }^{25}$ However, data on organ system involvement at study entry could not be used to predict which affected organ system 
would be the primary cause of death. In another study ${ }^{26}$ the extent of skin involvement was found to be the determining prognostic factor, together with scleroderma lung disease.

The multicentre severity score approach taken by the European, North American group $^{12}$ did show that relatively simple and generally available measures could be used to assess disease severity in SSc over a short period. We show the potential of a similar approach when applied to long term outcome. Such instruments will be important tools in future disease modifying treatment of SSc.

1 Medsger TA Jr, Masi AT. Epidemiology of systemic sclerosis (scleroderma). Ann Intern Med 1971;74:714-21.

2 LeRoy EC, Black C, Fleischmajer R, Jablonska S, Krieg T, Medsger TA Jr, et al. Scleroderma (systemic sclerosis) classification, subsets and pathogenesis. J Rheumatol 1988 ; 15:202-5.

3 Geirsson AJ, Danielsen R, Pétursson E. Left ventricular myocardial perfusion and function in systemic sclerosis before and after diltiazem treatment. Scand J Rheumatol 1996;25:317-20

4 Follansbee WP, Curtiss EI, Medsger TA Jr, Steen VD, Uretsky BF, Owens GR, et al. Physiologic abnormalities of cardiac function in progressive systemic sclerois with diffuse diac function in progressive systemic sclerois
scleroderma. N Engl J Med 1984;310:142-8

5 Kahn A, Devaux JY, Amor B, Menkes CJ, Weber S, Nitenberg A, et al. Nifedipine and thallium-201 myocardial perberg A, et al. Nifedipine and thallium-201 myocardial perfusion in progressive

6 Geirsson AJ, Åkesson A, Gustafson T, Elner Å, Wollheim FA. Cineradiography identifies esophageal candidiasis in progressive systemic sclerosis. Clin Exp Rheumatol 1989;7 43-6.

7 Åkesson A, Scheja A, Lundin A, Wollheim FA. Improved pulmonary function in systemic sclerosis after treatmen with cyclophosphamide. Arthritis Rheum 1994;37:729-35.

8 Geirsson AJ, Steinsson K, Gudmundsson S, Sigurdsson V. Systemic sclerosis in Iceland. A nationwide epidemiological study. Ann Rheum Dis 1994;53:502-5.

9 Hesselstrand R, Scheja A, Åkesson A. Mortality and causes of death in a Swedish series of systemic sclerosis patients. Ann Rheum Dis 1998;57:682-6.

10 Medsger TA, Rodnan GP, Robinson H. Survival with systemic sclerosis (scleroderma). A life-table analysis of systemic sclerosis (scleroderma). A life-table analysis of
clinical and demographic factors in 309 patients. Ann Intern Med 1971;75:369-76.
11 Farmer RG, Gifford RW, Hines EA. Prognostic significance of Raynaud's phenomenon and other clinical characteristics of systemic scleroderma. Circulation 1960;21:108895

12 Medsger TA Jr, Silman AJ, Steen VD, Black CM, Akesson A, Bacon PA, et al. A disease severity scale for systemic sclerosis: development and testing. J Rheumatol 1999;26: 2159-67.

13 Åkesson A, Wollheim FA. Organ manifestation in 100 patients with progressive systemic sclerosis. Br J Rheumatol 1989;28:281-6.

14 Masi AT, Rodnan GP, Medsger TA Jr, Altman R, D'Angelo $\mathrm{W}$, Fries J, et al. Preliminary criteria for classification of systemic sclerosis (scleroderma). Arthritis Rheum 1980;23: $581-90$

15 Åkesson A, Forsberg L, Hederström E, Wollheim F. Ultrasound examination of skin thickness in patients with progressive systemic sclerosis (scleroderma). Acta Radiol Diagn 1986;27:91-4.

16 Jonson B. A method for determination of pulmonary elastic recoil and resistance at a regulated flow rate. Scand J Clin Lab Invest 1969;24:115-25.

17 Åkesson B, Florén CH. Use of the triolein breath test for demonstration of fat malabsorption in coeliac disease. Scand J Gastroenterol 1984;19:307-14.

18 Silman A. Scleroderma - demographics and survival. J Rheumatol 1997;24(suppl 48):58-61.

19 Nagy Z, Cziriák L. Predictors of survival in 171 patients with systemic sclerosis (scleroderma).Clin Rheumatol 1997;16:454-60.

20 Steen VD, Medsger TA Jr, Osial TA, Ziegler GL, Shapiro AP, Rodnan GP. Factors predicting development of renal involvement in progressive sclerosis. Am J Med 1984;76: $779-86$.

21 Steen VD, Medsger TA Jr. Severe restrictive lung disease in systemic sclerosis (SSc). Arthritis Rheum 1994;37:1283-9.

22 Bryan C, Howard Y, Brennan P, Black C, Silman A. Survival following the onset of scleroderma: results from a retrospective inception cohort study of the UK patient population. Br J Rheumatol 1996;35:1122-6.

23 Bennett R, Bluestone R, Holt PJL, Bywaters EGL. Survival in scleroderma. Ann Rheum Dis 1971;30:581-8.

24 Steen VD, Medsger TA Jr. Epidemiology and natural history of systemic sclerosis. Rheum Dis Clin North Am 1990;16: $1-10$

25 Altman RD, Medsger TA Jr, Bloch DA, Michel BA. Predictors of survival in systemic sclerosis (scleroderma). Arthritis Rheum 1991;34:403-13.

26 Simeon CP, Armadans L, Fonollosa V, Vilardell M, Candell J, Tolosa C, et al. Survival prognostic factors and markers of morbidity in Spanish patients with systemic sclerosis. Ann Rheum Dis 1997;56:723-8. 